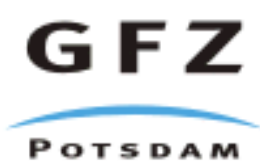

Originally published as:

Ballani, L., Wardinski, I., Stromeyer, D., Greiner-Mai, H. (2003): Time structure of the 1991 magnetic jerk in the core-mantle-boundary zone by inverting global magnetic data supported by satellite measurements, EOS, Transactions, American Geophysical Union, Suppl., Vol. 84(46), F548, 2003, AGU 2003 Fall Meeting (San Francisco, USA 2003) 


\title{
Time structure of the 1991 magnetic jerk in the core-mantle boundary zone by inverting global magnetic data supported by satellite measurements
}

\author{
Ludwig Ballani, Ingo Wardinski, Dietrich Stromeyer, and Hans Greiner-Mai \\ GeoForschungsZentrum Potsdam, Telegrafenberg, D-14473 Potsdam, Germany, \\ bal@gfz-potsdam.de
}

Summary. New global magnetic data - Gauss coefficients up to degree and order 5, monthly values from 1980 to 2000, fitted to global data and partly based on highquality satellite vector data of Magsat and CHAMP/ØRSTED - are processed with a recent non-harmonic downward continuation method (Ballani et al. 2002). Using a weakly conducting mantle and the highly conducting fluid in the outer core we investigate the temporal structure of the 1991 jerk below some geomagnetic stations calculating the component $\mathrm{dY} / \mathrm{dt}$ at the core-mantle boundary and underneath in different depths of the fluid outer core assuming fluid velocity there. The jerk structure dissolves and differs considerably in magnitude and in phase from the harmonically downward continued component.

Key words: CHAMP, Magsat, ØRSTED, geomagnetic jerk, Gauss coefficients, downward continuation, core-mantle boundary, fluid outer core

\section{Introduction}

Geomagnetic jerks are rapid changes in the secular variation of the Earth's magnetic field and are most easily seen in the first time derivative of the East component Y (Courtillot et al. 1978, Macmillan 1996). New global model data (Gauss coefficients) are the prerequisite for applying a recently developed rigorous inverse approach for downward continuation of the poloidal field to the core-mantle boundary (CMB). This approach facilitates to investigate the jerk morphology at the $\mathrm{CMB}$ and the region beneath and provides a new view of the features of the field near to the sources, if a passive layer or a simple-structured velocity distribution is assumed there.

\section{Global model data}

The input quantities for the non-harmonic downward continuation method (Ballani et al. 2002) are the Gauss coefficients $g_{n m}(t), h_{n m}(t)$. The calculation is done in a separate modelling process (Wardinski \& Holme 2003). As geomagnetic data we use observatory quiet monthly means, if not available 
Table 1. Conductivity $(\sigma)$ values for different shells and velocity $\omega$ in the upper core layer $\left(\mathrm{R}_{\mathrm{E}}=6370 \mathrm{~km}, \mathrm{R}_{\sigma}=5480 \mathrm{~km}, \mathrm{R}_{\mathrm{c}}=3485 \mathrm{~km}(\mathrm{CMB})\right)$

\begin{tabular}{lll}
\hline shell & $\sigma\left[\Omega^{-1} \mathrm{~m}^{-1}\right]$ & $\omega\left[10^{-3} \mathrm{rad} /\right.$ year $]$ \\
\hline \hline $\mathrm{R}_{\mathrm{E}} \geq \mathrm{r}>\mathrm{R}_{\sigma}$ & 0 & 0 \\
\hline $\mathrm{R}_{\sigma} \geq \mathrm{r}>\mathrm{R}_{\mathrm{c}}+2 \mathrm{~km}$ & $10 *\left(\mathrm{R}_{\mathrm{c}} / \mathrm{r}\right)^{5}$ & 0 \\
$\mathrm{R}_{\mathrm{c}}+2 \mathrm{~km} \geq \mathrm{r} \geq \mathrm{R}_{\mathrm{c}}$ & $1 * 10^{5}$ & 0 \\
\hline $\mathrm{R}_{\mathrm{c}}>\mathrm{r} \geq \mathrm{R}_{\mathrm{c}}-20 \mathrm{~km}$ & $2 * 10^{5}$ & -1.745 \\
\hline
\end{tabular}

annual means are used instead. With these data first-differences ('secular variations') are formed : Monthly means are treated by the n-step difference filter, e. g.

$$
\mathrm{dY} / \mathrm{dt}=\mathrm{Y}(\mathrm{t}+\mathrm{n} / 2)-\mathrm{Y}(\mathrm{t}-\mathrm{n} / 2), \mathrm{n}=12
$$

Annual means are treated using, e. g. $d Y / d t=Y(t)-Y(t-1)$. The geomagnetic potential is decomposed to spherical harmonics up to degree and order 5 and expanded in time by a basis of cubic B-splines with a knot separation of 1 year (Bloxham \& Jackson 1992). The model is fitted to the data in the linear least squares sense, where we minimize the misfit between data and model, the spatial and temporal roughness and the deviation from a priori models at 1980 (Magsat) and 2000 (CHAMP and ØRSTED) using special norms and damping parameters. The final model is achieved by an iteratively re-weighting scheme (for more details see Wardinski \& Holme in this volume). Further input quantities (see table 1 ) are the core radius $R_{c}, R_{\sigma}$ as assumed upper bound for the conducting shell and conductivity values, which are based on laboratory experiments for $\mathrm{R}_{\sigma} \geq \mathrm{r}>\mathrm{R}_{\mathrm{c}}+2 \mathrm{~km}$ (Shankland et al. 1993) while its value in $R_{c}+2 \mathrm{~km} \geq \mathrm{r} \geq \mathrm{R}_{\mathrm{c}}$ is suggested by $\mathrm{D}$ " theories and electromagnetic core-mantle coupling (Buffett 1992, Holme 1998). The angular velocity $\omega$ in the layer beneath the $\mathrm{CMB}$ was selected corresponding to the mean westward drift as major part of the secular variation.

\section{Downward continuation theory}

We apply the theory, presented in detail in (Ballani et al. 2002) and in extended form for a rotating fluid upper core layer with prescribed velocity in (Greiner-Mai et al. 2003), for the downward continuation of the quantity $\mathrm{dY} / \mathrm{dt}$. The vectorial induction equation (B magnetic flux, $\sigma=\sigma(\mathrm{r})$ conductivity, v velocity field)

$$
-\nabla \times\left(1 /\left(\mu_{0} \sigma\right) \nabla \times \mathbf{B}\right)+\nabla \times(\mathbf{v} \times \mathbf{B})=\dot{\mathbf{B}}, \quad \nabla \cdot \mathbf{B}=0
$$

is decomposed to poloidal and toroidal parts $\mathbf{B}=\mathbf{B}_{\mathbf{p}}+\mathbf{B}_{\mathbf{t}}=\nabla \times(\nabla \times \mathbf{r S})+$ $\nabla \times \mathbf{r T}$ with scalar functions $\mathrm{S}, \mathrm{T}$. Only the poloidal part with the expanded function $\mathrm{S}$ 
$\mathrm{S}(\mathrm{r}, \vartheta, \varphi, \mathrm{t})=\sum_{\mathrm{n}, \mathrm{m}}\left(\mathrm{S}_{\mathrm{nm}}^{\mathrm{c}}(\mathrm{r}, \mathrm{t}) \cos \mathrm{m} \varphi+\mathrm{S}_{\mathrm{nm}}^{\mathrm{s}}(\mathrm{r}, \mathrm{t}) \sin \mathrm{m} \varphi\right) \mathrm{P}_{\mathrm{nm}}(\cos \vartheta)$ is considered here. Strictly, the downward continuation problem is an initialboundary value problem with two boundary conditions both at the same (outer) radius (here: $\mathrm{R}_{\sigma}$, see table 1 ). We search its solution in the form

$$
\begin{gathered}
\mathrm{U}(\mathrm{r}, \mathrm{t}):=\mathrm{S}_{\mathrm{nm}}^{\mathrm{c}}(\mathrm{r}, \mathrm{t})+\mathrm{i} \mathrm{S}_{\mathrm{nm}}^{\mathrm{s}}(\mathrm{r}, \mathrm{t}), \text { with } \mathrm{R}_{\mathrm{oc}} \leq \mathrm{r} \leq \mathrm{R}_{\sigma}, 0 \leq \mathrm{t} \leq \mathrm{T}, \mathbf{v}=(0,0, \omega(\mathrm{r})) \times \mathbf{r} \\
\mathrm{U}_{\mathrm{rr}}+(2 / \mathrm{r}) \mathrm{U}_{\mathrm{r}}+\left(-\mathrm{n}(\mathrm{n}+1) / \mathrm{r}^{2}+\mathrm{im} \mu_{0} \sigma(\mathrm{r}) \omega(\mathrm{r})\right) \mathrm{U}=\mu_{0} \sigma(\mathrm{r}) \mathrm{U}_{\mathrm{t}} \\
\mathrm{U}\left(\mathrm{R}_{\sigma}, \mathrm{t}\right)=\phi(\mathrm{t}), \quad \mathrm{U}_{\mathrm{r}}\left(\mathrm{R}_{\sigma}, \mathrm{t}\right)+\left((\mathrm{n}+1) / \mathrm{R}_{\sigma}\right) \mathrm{U}\left(\mathrm{R}_{\sigma}, \mathrm{t}\right)=0, \quad \mathrm{U}(\mathrm{r}, 0)=\psi(\mathrm{r})
\end{gathered}
$$

where $\mathrm{U}_{\mathrm{r}}=\partial \mathrm{U} / \partial \mathrm{r}$ etc. The input function $\phi(\mathrm{t})$ is derived from Gauss coefficients. Calculating the functions $\mathrm{S}_{\mathrm{nm}}^{\mathrm{c}, \mathrm{s}}\left(\mathrm{R}_{\mathrm{oc}}, \mathrm{t}\right), \mathrm{R}_{\mathrm{oc}} \leq \mathrm{R}_{\mathrm{c}}$, the downward continuation of all field components of $\mathbf{B}_{\mathbf{p}}$ to the CMB (taking $\omega(\mathrm{r})=0$ ) as well as deeper into the fluid outer core upper layer is possible. For the jerk studies we first compute the $\mathrm{Y}=\mathrm{B}_{\varphi}$ component by the $\mathrm{S}_{\mathrm{nm}}^{\mathrm{c}, \mathrm{s}}\left(\mathrm{R}_{\mathrm{oc}}, \mathrm{t}\right)$ functions and spherical coordinates $(\vartheta, \varphi)$

$\mathrm{Y}=(1 / \mathrm{r}) \sum_{\mathrm{n}=1}^{\mathrm{N}} \sum_{\mathrm{m}=0}^{\mathrm{n}}\left(\left(\partial / \partial \mathrm{r}\left(\mathrm{rS}_{\mathrm{nm}}^{\mathrm{s}}\right) \cos \mathrm{m} \varphi-\partial / \partial \mathrm{r}\left(\mathrm{rS}_{\mathrm{nm}}^{\mathrm{c}}\right) \sin \mathrm{m} \varphi\right) \mathrm{m} \mathrm{P}_{\mathrm{nm}}(\cos \vartheta) / \sin \vartheta\right)$

Finally, the derivative $\mathrm{dY} / \mathrm{dt}$ is realized by the n-step difference filter eq.(1).

\section{Temporal structure of $\mathrm{dY} / \mathrm{dt}$ at the CMB - the 1991 jerk}

Results for $\mathrm{dY} / \mathrm{dt}$ at four geomagnetic stations can be seen in the figs. 1 and 2 . In (a), the secular variation at the Earth's surface predicted by the model are compared with the observatory data to see the ability to reproduce the jerk or in general the low-frequency course of the model data between 1985 and 1995 . Their limited degree 5 guarantees that the visible effect mainly originates from the deep earth interior. Figs. 1 and 2 (b) compare the non-harmonic downward continuation to the $\mathrm{CMB}$ and the application of the often used harmonic downward continuation which ignores any mantle conductivity. The high sensibility of the conductivity on the $\mathrm{dY} / \mathrm{dt}$ component can be seen in the clearly differing order of magnitudes and the phase shifts which is in addition based on a different weighting of the single degree and order parts. As an application of the extended non-harmonic downward continuation theory to the outer core upper layer Figs. 1 and 2 (c) give the possible jerk component for three depths. High conductivity combined with an assumed velocity (for the first $20 \mathrm{~km} \omega=$ const is sufficient) changes the amplitude to higher scales of magnitude. These results can be considered as an illustrative numerical experiment possibly near to the "sources" of jerks and therefore useful for further modelling. It can be observed that the difference in the jerk data, seen at the Earth surface, of relatively near stations, as Niemegk and Chambonla-Foret, disappeares nearer to the supposed source region where the curves 

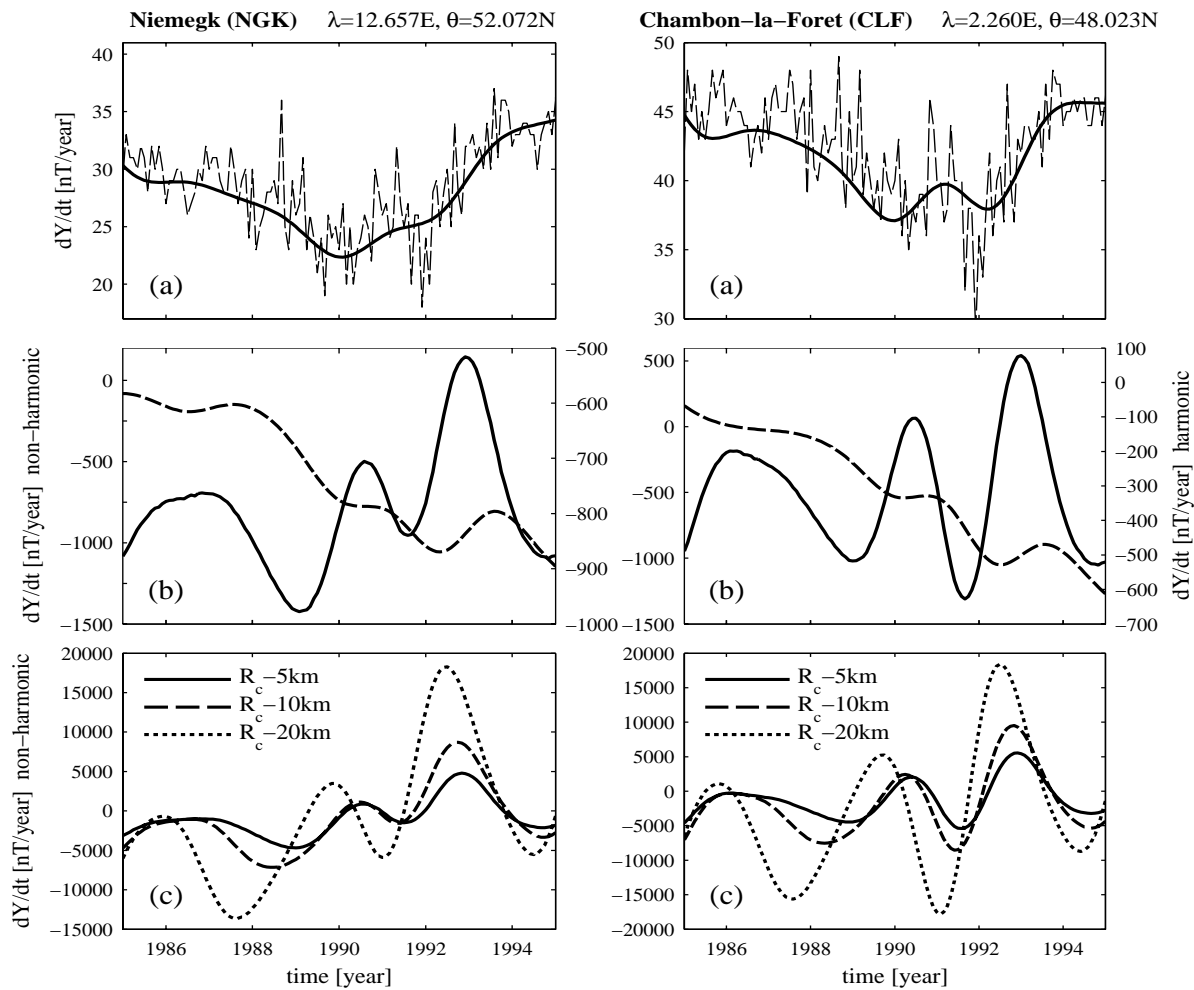

Fig. 1. Component $\mathrm{dY} / \mathrm{dt}$ at the stations Niemegk and Chambon-la-Foret: (a) Derived from observatory data (dashed line) and global model data derived from Gauss coefficients $(n, m \leq 5)$ at the earth surface (solid line) (b) Harmonic (dashed line, right scale) and non-harmonic (solid line, left scale) downward continuation of the global model data to the CMB (c) Non-harmonic downward continuation of global model data to three depths below the CMB.

(note the different vertical scales)

get a greater similarity.

By Fig.3 we show some synthetic single oscillation results to capture the "spectral characteristic" of a jerk: value of amplitude and phase shift. This feature is two-faced: the jerk can be understood as a "longperiodic" trend changing process and, on the other hand, concerning the decadal variations as a very short periodic event most visible in the $\mathrm{dY} / \mathrm{dt}$ component. Fig. 3 tries to catch this phenomenon comparing the behaviour of oscillations with periods between 3 years and 100 years. 

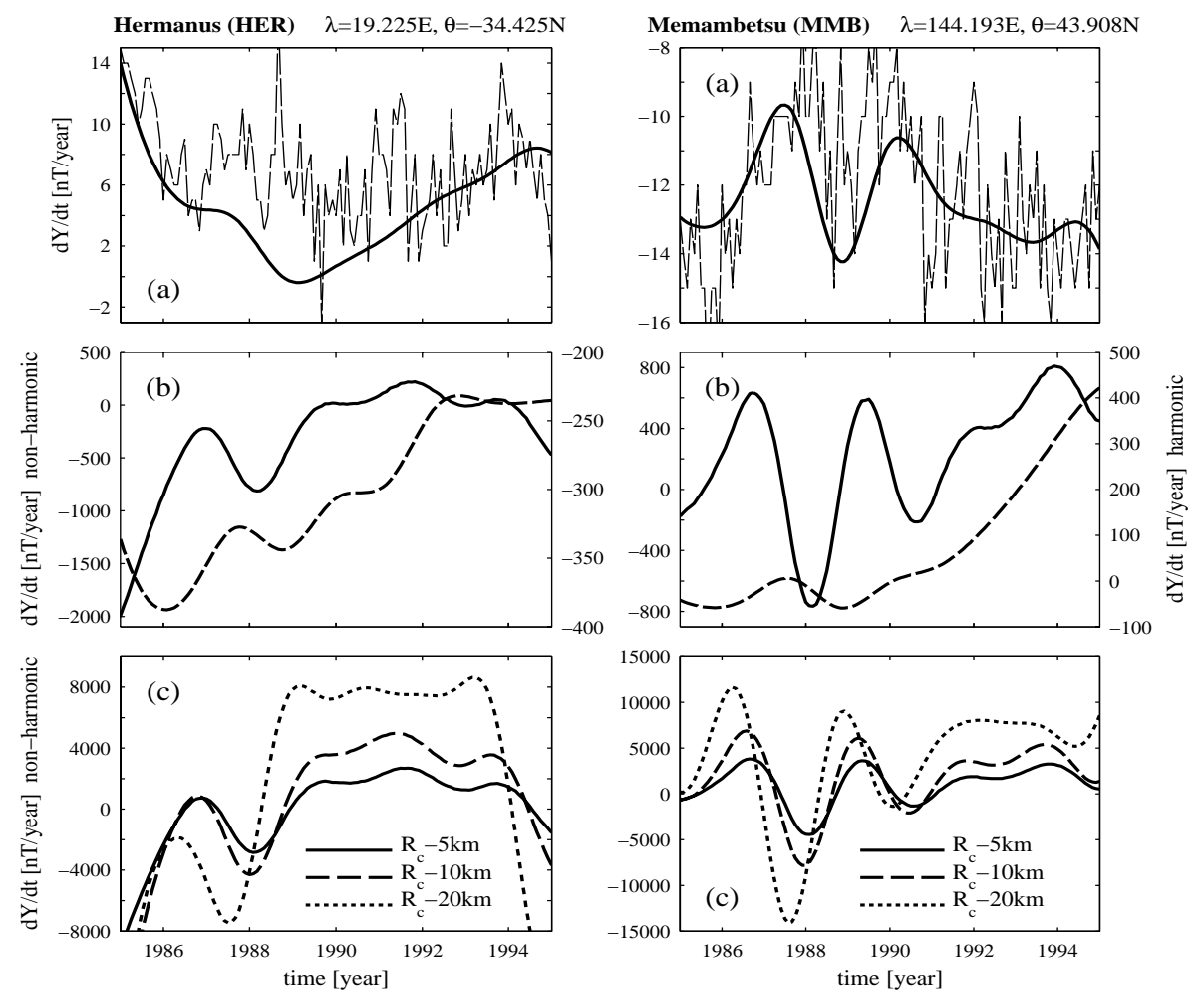

Fig. 2. Component dY/dt at the stations Hermanus and Memambetsu: (a) Derived from observatory data (dashed line) and global model data derived from Gauss coefficients $(\mathrm{n}, \mathrm{m} \leq 5)$ at the earth surface (solid line) (b) Harmonic (dashed line, right scale) and non-harmonic (solid line, left scale) downward continuation of the global model data to the CMB (c) Non-harmonic downward continuation of global model data to three depths below the CMB. (note the different vertical scales)

\section{Conclusions}

The $\mathrm{dY} / \mathrm{dt}$ component $\left(\dot{\mathrm{B}}_{\varphi}\right)$ derived from the Gauss coefficients has the typical jerk structure at geomagnetic observatories. We obtained the jerk structure by a spherical harmonic expansion limited to degree and order $n=m=5$ from globally distributed observatory data. This indicates that the origin of this signal is coming with the utmost probability from the deep Earth's interior.

Secondly, we apply the method of non-harmonic downward continuation to calculate the poloidal part of $\dot{\mathrm{B}}_{\varphi}$ at the $\mathrm{CMB}$ in a rigorous inverse way. This creates a basis for a detailed and geophysically founded study of the magnetic jerk of 1991 in the deep Earth' interior and can contribute to finding the causing mechanism. Compared with the harmonically downward contin- 

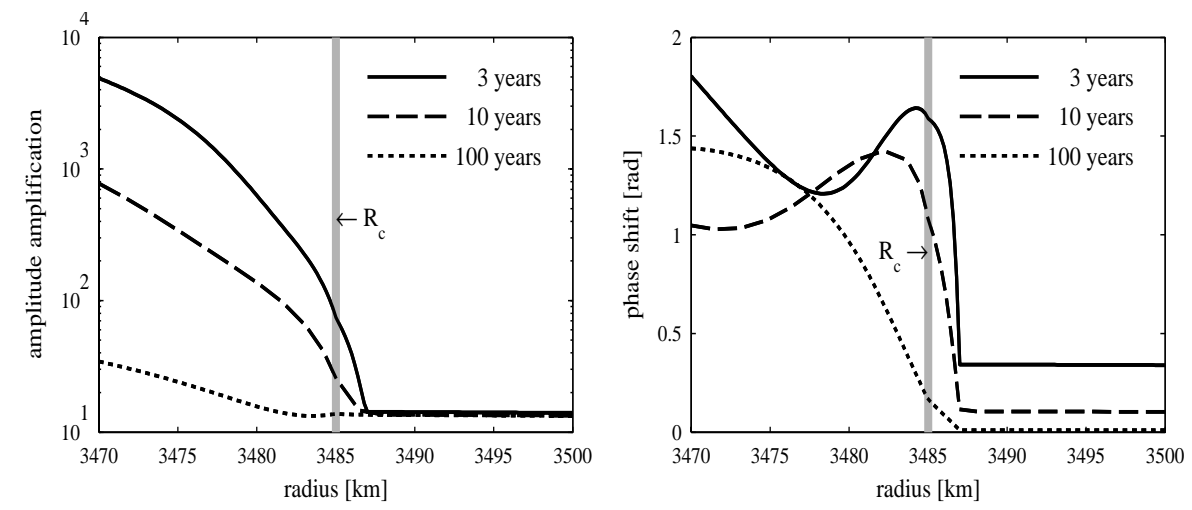

Fig. 3. $\mathrm{dY} / \mathrm{dt}$ set up as a single oscillation: Amplitude and phase for periods of 3,10 and 100 years in depths around the $\mathrm{CMB}$, normalized at $\mathrm{R}_{\mathrm{E}}$ by 1 and 0 , respectively.

ued jerk there is a completely other weighting of the degree portions by the non-harmonic procedure which, in addition, allows more realistic geophysical assumptions to be included. Thus, the results for the sensitive $\dot{\mathrm{B}}_{\varphi}$ component are much larger changes in the order of magnitude combined with significant phase shifts. Moreover, the initial jerk structure dissolves and vanishes completely, so that no simple function type can be assigned to it, and some earlier speculations about its morphology in the CMB region and/or physical causes should be reconceived.

Although some basic assumptions (about $\sigma(\mathrm{r})$ and $\omega$ ) are not proven yet, our study of the jerk in different depths of a fluid-outer-core upper layer can be considered as a first numerical experiment giving indications for a better understanding of the jerk phenomenon.

Acknowledgement. We thank our colleagues Veronika Söllner and Hans-Joachim Kühn for their kind technical help and an unknown reviewer for some suggestions of improvement.

\section{References}

1. Ballani L, Greiner-Mai H \& Stromeyer D (2002) Determining the magnetic field in the core-mantle-boundary zone by non-harmonic downward continuation. Geophys J Int 149: 374-389.

2. Bloxham J \& Jackson A (1992) Time-dependent mapping of the magnetic field at the core-mantle boundary. J Geophys Res 97: 19,537-19,563.

3. Buffett BA (1992) Constraints on magnetic energy and mantle conductivity from the forced nutations of the Earth. J Geophys Res 97: 19,581-19,597.

4. Courtillot V, Ducruix J \& Le Mouël J-L (1978) Sur une accélération récente de la variation séculaire du champ magnétique terrestre. C R Acad Sci D 287: 1095-1098. 
5. Greiner-Mai H, Ballani L, \& Stromeyer D (2003) The poloidal geomagnetic field in a differentially rotating upper core layer. Geophys J Int, submitted.

6. Holme R (1998) Electromagnetic core-mantle coupling - II. Probing deep mantle conductance. The Core-Mantle Boundary Region. In: Gurnis M, Wysession ME, Knittle E, Buffett BA (eds), The Core-Mantle Boundary Region, American Geophysical Union, Washington, pp. 139-151.

7. Macmillan S (1996) A geomagnetic jerk for the early 1990's. Earth Planet Sci Lett 137: 189-192.

8. Shankland TJ, Peyronneau J, \& Poirier JP (1993) Electrical conductivity of the Earth's lower mantle. Nature 366: 453-455.

9. Wardinski I \& Holme R (2003) Decadal and Subdecadal Secular Variation of Main Geomagnetic Field. In: Reigber C, Lühr H, Schwintzer P (eds), First CHAMP Mission Results for Gravity, Magnetic and Atmospheric Studies, Springer-Verlag, Berlin et al, pp. 226 - 232. 